\title{
Comparative Transcriptional and Anatomical Analyses of Tolerant Rough Lemon and Susceptible Sweet Orange in Response to 'Candidatus Liberibacter asiaticus' Infection
}

\author{
Jing Fan, ${ }^{1,2}$ Chunxian Chen, ${ }^{2}$ Qibin Yu, ${ }^{2}$ Abeer Khalaf, ${ }^{2,3}$ Diann S. Achor, ${ }^{2}$ Ron H. Brlansky, ${ }^{2}$ \\ Gloria A. Moore, ${ }^{3}$ Zheng-Guo Li, ${ }^{1}$ and Frederick G. Gmitter, Jr. ${ }^{2,3}$ \\ ${ }^{1}$ Chongqing University, College of Bioengineering, Key Laboratory of Biorheological Science and Technology, Ministry \\ of Education, Chongqing, 400030, China; ${ }^{2}$ University of Florida, Institute of Food and Agricultural Sciences, Citrus \\ Research and Education Center, Lake Alfred 33850, U.S.A.; ${ }^{3}$ University of Florida, Plant Molecular and Cellular Biology \\ Program, Horticultural Sciences Department, Gainesville 32611, U.S.A.
}

Submitted 11 June 2012. Accepted 10 July 2012.

\begin{abstract}
Although there are no known sources of genetic resistance, some Citrus spp. are reportedly tolerant to huanglongbing (HLB), presumably caused by 'Candidatus Liberibacter asiaticus'. Time-course transcriptional analysis of tolerant rough lemon (Citrus jambhiri) and susceptible sweet orange (C. sinensis) in response to ' $C a$. $\mathrm{L}$. asiaticus' infection showed more genes differentially expressed in HLB-affected rough lemon than sweet orange at early stages but substantially fewer at late time points, possibly a critical factor underlying differences in sensitivity to ' $\mathrm{Ca}$. L. asiaticus'. Pathway analysis revealed that stress responses were distinctively modulated in rough lemon and sweet orange. Although microscopic changes (e.g., callose deposition in sieve elements and phloem cell collapse) were found in both infected species, remarkably, phloem transport activity in midribs of source leaves in rough lemon was much less affected by HLB than in sweet orange. The difference in phloem cell transport activities is also implicated in the differential sensitivity to HLB between the two species. The results potentially lead to identification of key genes and the genetic mechanism in rough lemon to restrain disease development and maintain (or recover) phloem transport activity. These potential candidate genes may be used for improving citrus tolerance (or even resistance) to HLB by genetic engineering.
\end{abstract}

Citrus huanglongbing (HLB) or citrus greening is a highly destructive disease in many citrus production areas worldwide. It was first found in China in the early 20th century (Zhao 1981) and recently discovered in Brazil and Florida (United States) (Bove 2006), and threatens the future viability of the citrus industries. This disease is presumably caused by ' $\mathrm{Candi-}$ datus Liberibacter spp.', a phloem-inhabiting $\alpha$-proteobacteria, and is transmitted by two kinds of phloem-feeding citrus psyllids, Diaphorina citri and Trioza erytreae. HLB results in a range of symptoms that vary with citrus varieties and species,

Current address for J. Fan: Sichuan Agricultural University, Rice Research Institute, Chengdu 611130, China.

Corresponding authors: F. G. Gmitter, Jr.; E-mail: fgmitter@ufl.edu; and Z.-G. Li; E-mail zhengguoli@cqu.edu.cn

* The $e$-Xtra logo stands for "electronic extra" and indicates twelve supplementary tables and two supplementary figures are published online. including yellow shoots, blotchy mottled leaves, lopsided fruit, and severe tree decline. All known citrus species and cultivars can be affected by HLB. However, host response to infection and development of symptoms in greenhouse conditions or in the field are significantly different among the various citrus species (Folimonova et al. 2009; Koizumi et al. 1993), and some citrus species and relatives were considered tolerant to this disease. Generally, sweet orange and grapefruit are very susceptible; some lemon and lime display tolerance, evidenced by less severe symptoms and much slower or no decline in both greenhouse and field plantings; and Poncirus trifoliata appears to be most tolerant to HLB; however, the work supporting the concept was not reproducible (Folimonova et al. 2009).

Disease symptom development is considered to be the consequence of molecular, cellular, and physiological changes and defense responses in a plant host interacting with a pathogen (O'Donnell et al. 2003). In incompatible plant-microbe interactions, defense responses include hypersensitive reaction resulting in localized cell death, cell wall modifications, and synthesis of plant defense molecules (Hammond-Kosack and Jones 1996). In contrast, suppression of host responses such as basal defenses is crucial for pathogenesis in compatible microbe-plant interactions (Nomura et al. 2005). Understanding host response following 'Candidatus Liberibacter asiaticus' inoculation and subsequent progression of HLB could aid the development of new strategies to control the disease. Two research groups have reported on the global gene expression changes of sweet orange in response to ' $\mathrm{Ca}$. L. asiaticus' infection, showing that genes involved in a number of processes such as cell defense, photosynthesis, and carbohydrate metabolism were differentially expressed (Albrecht and Bowman 2008; Kim et al. 2009). Albrecht and Bowman (2008) conducted experiments covering the early and late time points of HLB infection but they applied a pooling strategy to the RNA samples, which might result in loss of important gene expression information and increase of false positives (Affymetrix 2004). Kim and associates (2009) only investigated the transcriptional profile at a late stage of the disease development. A recent study reported the transcriptional changes in tolerant US-897 (Citrus reticulata Blanco $\times P$. trifoliata L. Raf.) and susceptible 'Cleopatra' mandarin in response to the infection of ' $\mathrm{Ca}$. L. asiaticus' only at an advanced stage of HLB disease development, when symptoms were fully expressed (Albrecht and Bowman 2011b). Because US-897 is an intergeneric hybrid 
of Citrus spp. and Poncirus spp., comparing host responses throughout a time course of ' $\mathrm{Ca}$. L. asiaticus' infection between two more closely related Citrus varieties should provide a more complete understanding of the disease mechanisms in cultivated Citrus spp. and may lead to a strategy to manage the disease by increasing such tolerance in highly susceptible cultivars through adjusted horticultural practices or genetic modifications.

Rough lemon is considered tolerant to HLB, compared with sweet orange and other highly susceptible varieties. Once infected and symptomatic, rough lemon can be rejuvenated by continual growth of new shoots with few or no foliar symptoms and repeat in many growing seasons, whereas sweet orange exhibits continuous quick growth retardation and eventual die back. US-897 is tolerant to the infection of ' $\mathrm{Ca}$. L. asiaticus' based on the observation that it exhibits no distinct disease symptoms associated with HLB, except for few foliar symptoms in a small number of plants at later stages of the disease (Albrecht and Bowman 2011a). The underlying mechanisms of recovery in ' $\mathrm{Ca}$. L. asiaticus'-infected rough lemon may be quite different from the tolerant response of US-897 (Albrecht and Bowman 2011b).

The objective of this study was to compare host responses to ' $C a$. L. asiaticus' between highly susceptible sweet orange $(C$. sinensis L. Osbeck) and tolerant rough lemon ( $C$. jambhiri Lush.) throughout the time course from inoculation to full dis- ease expression. Microarray analysis was carried out at 5, 17, and 27 weeks after inoculation (WAI) and at the time immediately before inoculation using the Affymetrix Citrus GeneChip. Phloem ultrastructure and phloem loading of rough lemon and sweet orange in response to ' $C a$. L. asiaticus' infection were also compared. These results will enhance understanding of HLB susceptibility and tolerance mechanisms in citrus, and lead to the development of new tools to improve citrus tolerance, possibly even to develop resistance, to this disease.

\section{RESULTS}

' $\mathrm{Ca}$. L. asiaticus' detection and HLB symptom development.

' $C a$. L. asiaticus' detection was conducted by quantitative real-time polymerase chain reaction (PCR). Because ' $\mathrm{Ca}$. L. asiaticus' is unevenly distributed in citrus (Teixeira et al. 2008), it is difficult to judge which plant contains more ' $\mathrm{Ca}$. L. asiaticus'. Therefore, we used the quantitative real-time PCR results (cycle threshold $\left[\mathrm{C}_{\mathrm{T}}\right]$ values) as qualitative data to confirm whether rough lemon and sweet orange plants were infected with ' $C a$. L. asiaticus' (i.e., whether ' $C a$. L. asiaticus' positive or not). In the three graft-inoculated rough lemon plants selected for microarray analysis, ' $\mathrm{Ca}$. L. asiaticus' was detected by quantitative real-time PCR around 20 WAI. In the three selected graft-inoculated sweet orange plants, one was confirmed to be ' $\mathrm{Ca}$. L. asiaticus' positive around $20 \mathrm{WAI}$ and
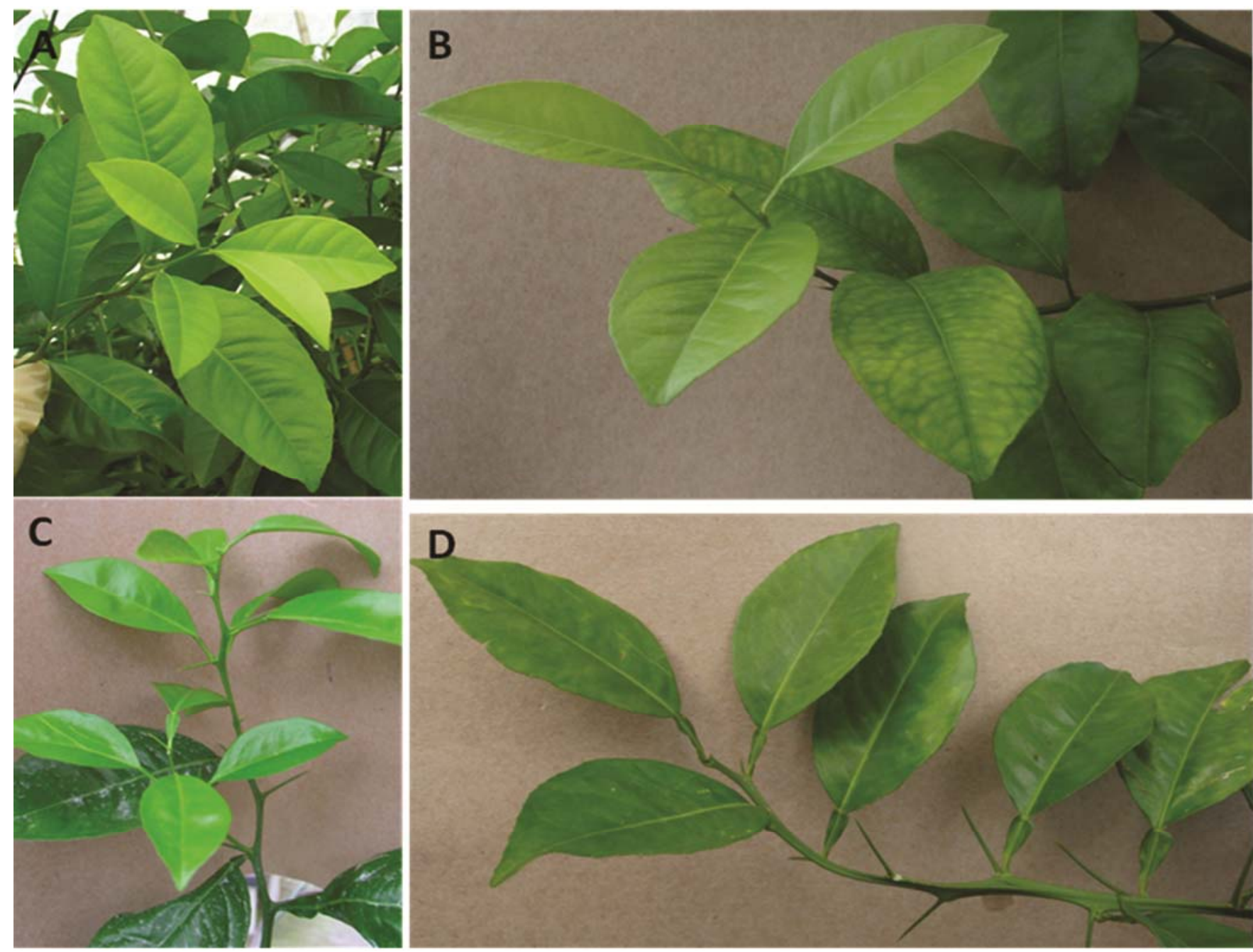

Fig. 1. Typical leaf symptoms of huanglongbing (HLB)-affected rough lemon and sweet orange around 27 weeks after inoculation (WAI). A, Branch from mock-inoculated rough lemon; B, branch from HLB-affected rough lemon showing disease-related symptoms on mature leaves and no symptoms on young leaves; C, branch from mock-inoculated sweet orange; D, branch from HLB-diseased sweet orange showing disease-related symptoms. 
the other two at 27 WAI. No HLB-specific symptoms were observed before 17 WAI for rough lemon and sweet orange; typical symptoms such as blotchy leaf mottle and yellowing emerged around 20 WAI and developed toward 27 WAI. Afterward, with severe and obvious blotchy mottle symptoms on mature and old leaves of sweet orange plants, their growth was significantly inhibited, rarely putting out new shoots toward the end of the experiment; however, rough lemon plants, without obvious inhibition of plant growth, kept flushing new shoots with few or no symptoms, although blotchy mottle was commonly found on mature and old leaves (Fig. 1). No ' $\mathrm{Ca}$. L. asiaticus' was detected in mock-inoculated rough lemon or sweet orange throughout the experiment.

\section{Overview of microarray analysis.}

The genome-wide Affymetrix citrus microarray, containing 33,879 citrus transcripts, was used to compare the global gene expression profiles of rough lemon and sweet orange representing tolerant and susceptible citrus, respectively, in response to ' $C a$. L. asiaticus' infection. Time-course experiments, including three time points $(5,17$, and $27 \mathrm{WAI})$ for each species, were conducted. $\log _{2}$-fold change of gene expression (' $\mathrm{Ca}$. L. asiaticus' inoculated versus mock inoculated) of each probe was obtained. The numbers of differentially expressed probes were displayed under two significance levels $(P \leq 0.05$ or false discovery rate $[\mathrm{FDR}] \leq 0.05)$, respectively, in combination with a cutoff value of twofold change (i.e., $\log _{2}$ ratio $\geq 1$ or $\log _{2}$ ratio $\leq-1$ ) (Fig. 2). There were 683, 411, and 1,055 probe sets in rough lemon and 181,1,037, and 3,476 probe sets in sweet orange differentially expressed $(P \leq 0.05)$ at 5,17 , and $27 \mathrm{WAI}$, respectively. Under more stringent criteria (i.e., FDR $\leq 0.05$ ), fewer differentially expressed probe sets were found (Fig. 2B). No significant changes of gene expression were displayed at 5 WAI for either rough lemon or sweet orange data sets (FDR $\leq$

A

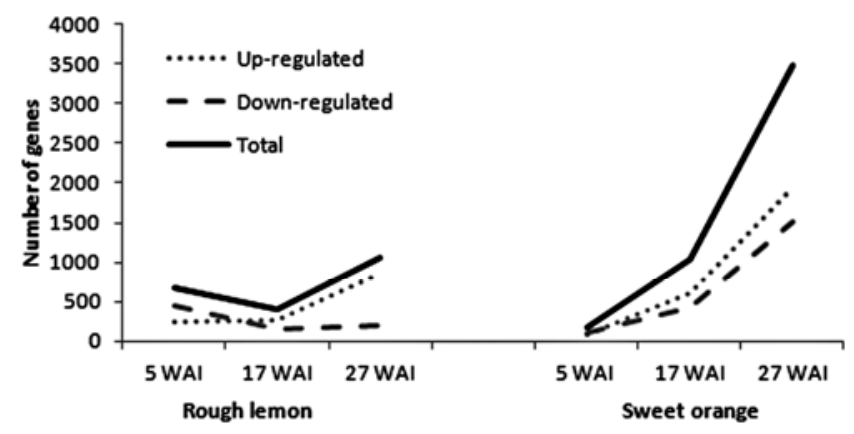

B

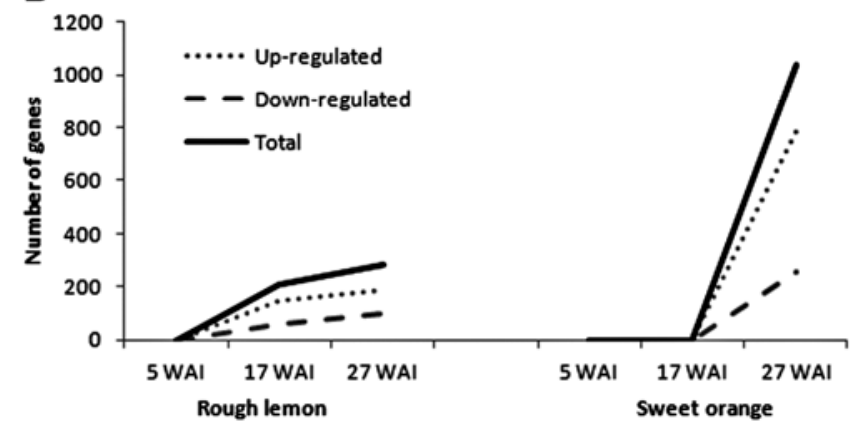

Fig. 2. Number of differentially expressed genes at each time point in the 'Candidatus Liberibacter asiaticus'-inoculated rough lemon and sweet orange versus their own mock-inoculated controls (fold change $\geq 2$ ) at the significant levels of $\mathbf{A}, P \leq 0.05$ or $\mathbf{B}$, false discovery rate (FDR) $\leq 0.05$. $\mathrm{WAI}=$ weeks after inoculation.
0.05). Only 1 probe set (Cit.39005.1.S1_at) was downregulated (FDR $\leq 0.05)$ at $17 \mathrm{WAI}$ in sweet orange but 207 probe sets showed changed expression levels at 17 WAI in rough lemon. Overall, upregulation predominated downregulation along with time for both species, except at $5 \mathrm{WAI}$ in rough lemon $(P \leq 0.05)$ (Fig. 2A). At $27 \mathrm{WAI}$, many more genes were differentially expressed in sweet orange than in rough lemon (Fig. 2).

Comparison of gene expression between rough lemon and sweet orange plants immediately before grafting inoculation was also conducted. In total, 351 genes were differentially expressed (fold change $\geq 2, P \leq 0.05$ ) in rough lemon compared with sweet orange independent of ' $\mathrm{Ca}$. L. asiaticus' infection (Supplementary Table S1). Among them, only 30 genes had change of expression $\geq$ fourfold. The transcriptional levels of 13 genes were more than fourfold higher in rough lemon compared with sweet orange. However, none of these genes was found to be modulated by ' $\mathrm{Ca}$. L. asiaticus' infection in either rough lemon or sweet orange (Supplementary Table S2). Among the 17 genes with higher basal expression in sweet orange compared with rough lemon, the most noteworthy was a gene coding for GAST1 protein homolog 1 (GASA1). It was more than 15-fold abundant in sweet orange than in rough lemon, and was induced by more than 11-fold in response to ' $\mathrm{Ca}$. L. asiaticus' infection in sweet orange (27 WAI) but not changed in ' $\mathrm{Ca}$. L. asiaticus'inoculated rough lemon. Four genes with unknown functions (Cit.842.1.S1_at, Cit.8198.1.S1_x_at, Cit.17803.1.S1_at, and Cit.20194.1.S1_at) shared a similar trend of expression with GASA1. They may be potential HLB-susceptible genes.

Significantly HLB-modulated pathways at each time point.

To provide a comparative overview of the responses to ' $\mathrm{Ca}$. L. asiaticus' in rough lemon and sweet orange across time points, a condensed heat-map-like display of changed pathways was generated by PageMan (Usadel et al. 2006). Here, the expression data of probe sets with $P \leq 0.05$ at each time point were used. These data files can be found in Supplementary Tables S3 to S8. The pathways showing qualitatively different or similar regulations in the two species across time points were revealed by visual inspection (Fig. 3). Pathways related to photosynthesis and response to heat stress were downregulated in both infected rough lemon and sweet orange compared with their own controls, although these changes were not shown at the same time points in the two species. It could be inferred that photosynthesis in HLB-affected citrus is inhibited to some extent, which agrees with the suggestion of Albrecht and Bowman (2008). However, many other processes were distinctively and differentially modulated by ' $\mathrm{Ca}$. L. asiaticus' infection in rough lemon and sweet orange. Notably, genes involved in cell wall-related pathways (e.g., cell wall pectin esterases) were mostly downregulated at the early stage (5 WAI) of infection in rough lemon and upregulated at the late stage (27 WAI); in contrast, a generally opposite trend was observed in the ' $C a$. L. asiaticus'-sweet orange interaction (Fig. 3). Different transcriptional changes were also observed in other gene functional categories (e.g., lipid metabolism, $\beta$ 1,3-glucan hydrolases, and GDSL-motif lipases). These differences were highlighted at $27 \mathrm{WAI}$, when typical HLB symptoms were already expressed in diseased plants. Interestingly, significant upregulation of both pathogenesis-related (PR) proteins and WRKY domain transcription factors were only observed at 27 WAI in sweet orange, indicating a strong stress response. Moreover, hormone metabolisms were differentially modulated in rough lemon and sweet orange (Fig. 3). It is noteworthy that, at the early time point of infection, genes related to abscissic acid metabolism showed coordinated upregulation in diseased rough lemon, whereas genes involved in the ethylene pathway 
DPS

major $\mathrm{CHO}$ metabolism
minor $\mathrm{C} H \mathrm{HO}$ metabolism

lipid metabolism

Dhormone metabolism

DRNA

protein

>stress

redox

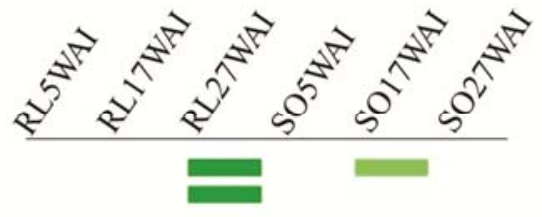

+ras

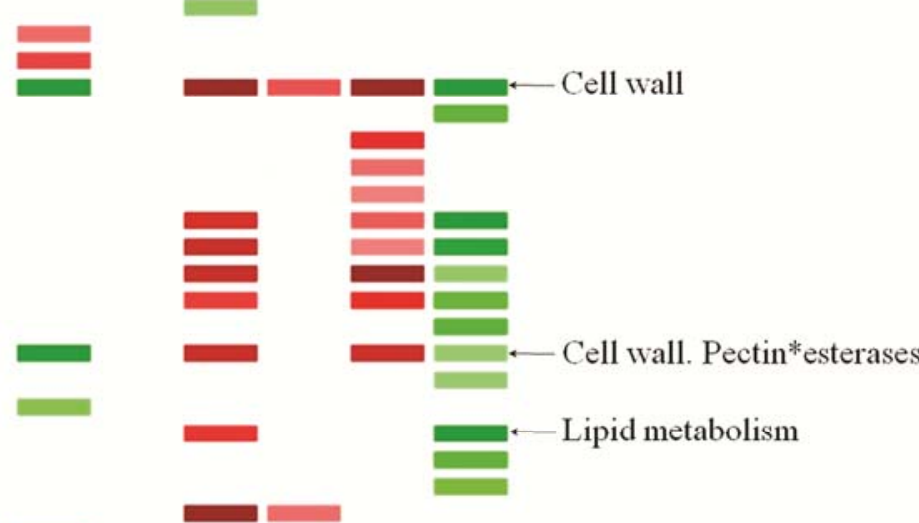

Ł Hormone metabolism. Abscisic acid

$\longleftarrow$ Hormone metabolism. Brassinosteroid

— Hormone metabolism. Ethylene

$\longleftarrow$ Hormone metabolism. Jasmonate
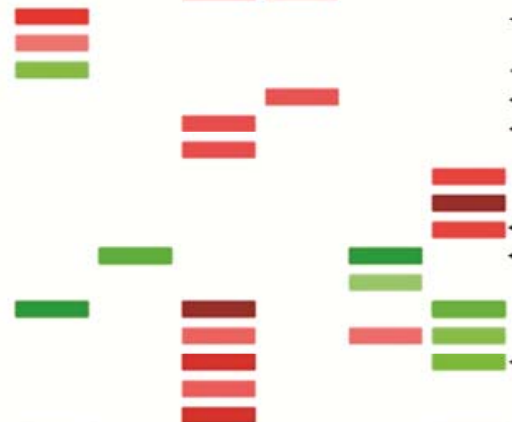

- Stress. Biotic. PR-proteins

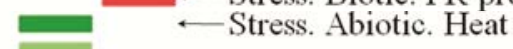

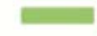

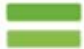

— Misc. Beta-1, 3-glucan hydrolases

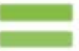

$\longleftarrow$ Misc. GDSL-motif lipase

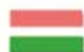

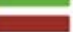

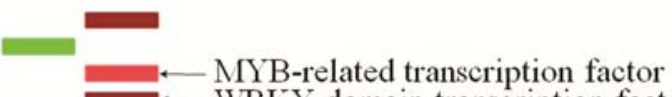

- MYB-related transcription factor
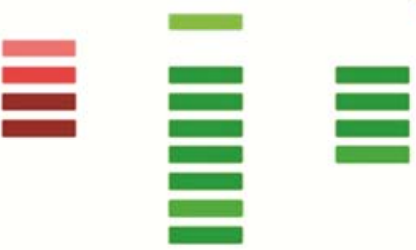

$\square$
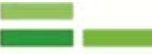

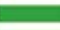

$=$

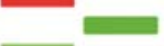

픈

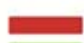

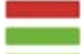

맘

>signaling

Dcell

transport

\section{not assigned}

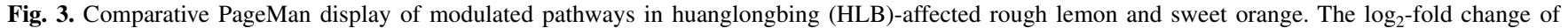
gene expression ('Candidatus Liberibacter asiaticus'-inoculated plants versus mock-inoculated controls) was input into PageMan and subjected to a Wilcoxon test. Results were shown as a false-color heat-map-like display. Pathways significantly upregulated are colored in red, while those colored in green are significantly downregulated. Pathways without significant changes are white. Names of pathways of interest are indicated on the right panel. RL5WAI, RL17WAI, and RL27WAI indicate 5, 17, and 27 weeks after inoculation (WAI) of rough lemon; SO5WAI, SO17WAI, and SO27WAI indicate 5, 17, and 27 WAI of sweet orange. PS, photosynthesis; CHO, carbohydrate. 
were mostly upregulated in infected sweet orange. These results suggest that rough lemon and sweet orange likely possess distinctive mechanisms in response to ' $\mathrm{Ca}$. L. asiaticus' infection. Other significantly changed functional gene categories, such as carbohydrate metabolism, signaling, protein, and transport, were also observed. A complete list of HLB-modulated pathways for both rough lemon and sweet orange data sets was provided in Supplementary Table S9.
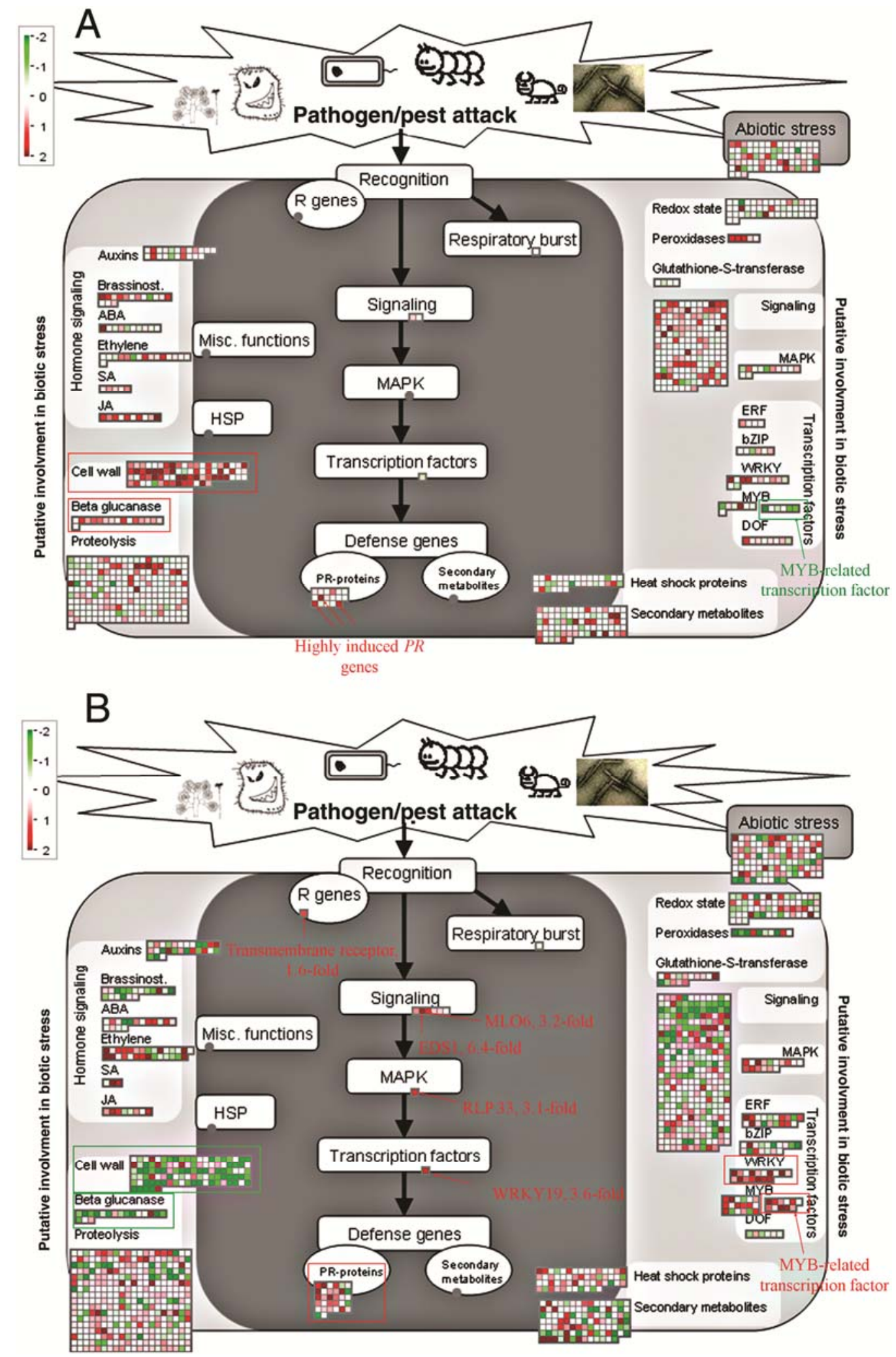

Fig. 4. Display of huanglongbing (HLB)-modulated stress responses at 27 weeks after inoculation (WAI) of A, rough lemon and $\mathbf{B}$, sweet orange data sets. The $\log _{2}$-fold change of gene expression ('Candidatus Liberibacter asiaticus'-inoculated plants versus mock-inoculated controls) was analyzed using MapMan. Small squares colored in red and green represent genes up- and downregulated, respectively. A false-color scale was used and all the values were given on a $\log _{2}$ scale. Color saturates at a fourfold change (i.e., $\log _{2}$ ratio $=2$ or -2 ). Red boxes and arrows indicate the upregulated processes and genes while green ones indicate the downregulated processes and genes. 
Differential stress responses of rough lemon and sweet orange to ' $\mathrm{Ca}$. L. asiaticus' infection.

Stress-response-related pathways, such as cell wall, hormone metabolism, and transcription factor families, displayed differential responses in HLB-affected rough lemon and sweet orange plants (Fig. 3). The differentially expressed genes associated with stress responses were mapped into the Biotic Stress Pathway using MapMan software (Thimm et al. 2004).

Cell wall metabolism was one of the most dramatically altered pathways in both HLB-affected rough lemon and sweet orange (Fig. 4; Supplementary Fig. S1). In rough lemon, 66, 23 , and 74 cell wall-related genes were differentially expressed at 5, 17, and 27 WAI, respectively. Most cell wall-related genes were downregulated at the early time point of ' $\mathrm{Ca}$. L. asiaticus' infection (5 WAI), whereas expression levels of a large number of cell wall genes were elevated toward 27 WAI. It is very interesting that an opposite trend was observed in sweet orange (i.e., coordinated upregulation at the beginning of ' $\mathrm{Ca}$. L. asiaticus' infection but downregulation at the late stage [27 WAI]). The expression data were presented in Supplementary Table S10. These modulated genes were categorized into a wide range of cell wall processes such as cell wall modification, cell wall proteins, cell wall pectin esterases, precursor synthesis, cellulose synthesis, and cell wall degradation. It is indicated that cell wall components and structures are likely undergoing dramatic changes in HLB-affected citrus. Expression levels of many cell wall genes were significantly altered as early as 5 WAI in rough lemon but not until 17 WAI in sweet orange, suggesting that earlier cell wall responses to ' $\mathrm{Ca}$. L. asiaticus' bacterium occurred in the former.

The most remarkable change of transcriptional profiling occurred at 27 WAI for both rough lemon and sweet orange,

Table 1. Huanglongbing (HLB)-modulated cell wall-associated genes at 27 weeks after inoculation (WAI) of both rough lemon and sweet orange data sets

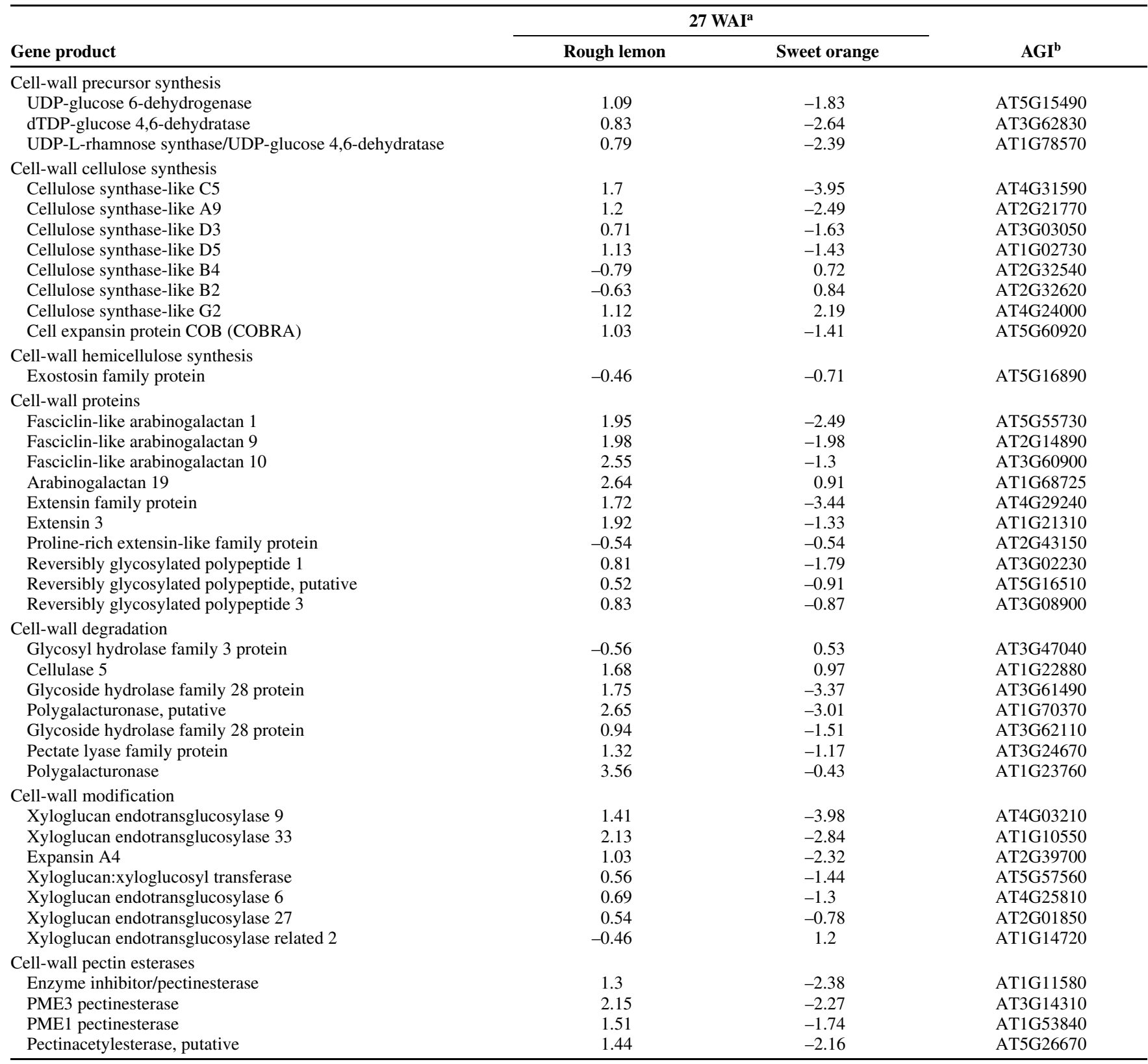

${ }^{a} \log _{2}$-fold change of gene expression ('Candidatus Liberibacter asiaticus' versus mock-inoculated control) at 27 WAI of rough lemon and sweet orange.

${ }^{\mathrm{b}}$ Arabidopsis Genome Initiative (AGI) numbers of Arabidopsis orthologs of HLB-modulated citrus genes. The differentially expressed probe sets from the Affymetrix Citrus GeneChip were annotated based on the closest hits in the Arabidopsis genome. Note that different probes can be matched to the same gene. In this case, the expression data of these probes were averaged. 
when ' $\mathrm{Ca}$. L. asiaticus' bacterium was detected and HLB symptoms appeared (Fig. 4). The results showed that 40 differentially expressed cell wall-associated genes were observed at 27 WAI in both data sets (Table 1). Of these, most genes increased their expression in affected rough lemon but were downregulated in diseased sweet orange. For instance, a group of genes encoding for arabinogalactan proteins (AGP) and xyloglucan endotransglycosylases (XET) were significantly induced or suppressed by more than twofold in HLB-affected rough lemon and sweet orange, respectively, compared with their own mockinoculated controls.

The transcriptional change of an important large enzyme family, $\beta$-1,3-glucanase, had a similar trend with the cell wallassociated genes in both data sets (Fig. 4). This is expected because $\beta$-1,3-glucanase is closely related to cell wall metabolism. Few changes of $\beta$-1,3-glucanase transcripts were observed at 5 and $17 \mathrm{WAI}$; dramatic changes appeared at $27 \mathrm{WAI}$, at which time both ' $\mathrm{Ca}$. L. asiaticus'-inoculated rough lemon and sweet orange expressed leaf yellowing and blotchy mottle symptoms. In all, $15 \beta$-1,3-glucanase genes showed upregulation at 27 WAI in diseased rough lemon; in contrast, the transcripts of $10 \beta-1,3$-glucanase decreased by two- to 10 -fold in infected sweet orange compared with the mock-inoculated control (Fig. 4).

PR proteins play an important role in plant defense against pathogens. However, no significant induction of $P R$ transcripts was observed at early stages (5 and $17 \mathrm{WAI}$ ) in either rough lemon- or sweet orange-' $\mathrm{Ca}$. L. asiaticus' interactions. By contrast, a disease resistance family protein and a trypsin and protease inhibitor family protein or Kunitz family protein were repressed by nearly four- and eightfold, respectively, at 5 WAI of infected rough lemon compared with the mock-inoculated control. At 27 WAI, more $P R$ genes were modulated in both infected rough lemon and sweet orange (Fig. 4). Among the 17 modulated $P R$ genes in rough lemon, only three disease resistance-responsive genes and a trypsin and protease inhibitor family gene or Kunitz family gene were significantly upregulated (fold change $\geq 2$ ). At $27 \mathrm{WAI}$ in sweet orange, 14 of the 32 differentially expressed $P R$ genes were induced by two- to eightfold (Fig. 4). These genes mostly belong to the coiled-coil nucleotide-binding site leucine-rich repeat (NBS-LRR) class and Toll interleukin-1 receptor NBS-LRR class of disease resistance gene families. Nevertheless, several $P R$ genes were downregulated (e.g., an acidic endochitinase gene and a disease resistance gene were repressed by 6.1- and 3.6-fold, respectively). Intriguingly, a resistance $(R)$-gene-mediated disease resistance pathway was turned on at 27 WAI in sweet orange (Fig. 4). Upstream of the defense genes, transcripts of genes homologous to Arabidopsis WRKY19 transcription factor, AtRLP33, EDS1, and a transmembrane receptor were induced by more than twofold (Fig. 4).

In addition, a set of MYB-related transcription factor genes displayed significant upregulation at 27 WAI of infected sweet orange (Fig. 4B). For instance, citrus orthologs of Arabidopsis LHY-, RVE1-, and CCA1-like transcription factor genes were induced by two- to fourfold. However, they were downregulated in infected rough lemon at both 17 and 27 WAI (Fig. 4A). MYB transcription factors play important roles in many physiological processes, such as light signaling pathway (Rawat et al. 2009) and stress response (Nagaoka and Takano 2003; Raffaele et al. 2008; Vailleau et al. 2002). Specifically, LHY-, RVE1-, and CCA1-like transcription factors play critical roles in regulating circadian rhythms (Rawat et al. 2009; Schaffer et al. 1998; Wang and Tobin 1998). Altered expression of these genes can cause abnormal circadian rhythms which, in turn, result in disorders of clock-regulated pathways, such as photosynthesis, transport of sugars, and starch metabolism
(Harmer et al. 2000). Interestingly, repression of photosynthesis pathway genes and disorders of carbohydrate metabolism (genes and metabolites) have been observed in HLB-affected sweet orange (Albrecht and Bowman 2008; Fan et al. 2010, 2011). It is suggested that the transcriptional changes of these MYB-related transcription factors may correlate to the interference of photosynthesis and carbohydrate metabolism in ' $\mathrm{Ca}$. L. asiaticus'-infected plants.

\section{Validation of microarray data \\ by quantitative reverse-transcription PCR.}

To validate the microarray data using quantitative reversetranscription (RT) PCR (qPCR), 18 genes distributed among different biological processes were selected, especially pathways significantly modulated in HLB disease progression such as carbohydrate metabolism, cell wall metabolism, or stress response. In total, 54 data points from different time points from both rough lemon and sweet orange data sets were included. The detailed information and expression data of the selected genes were presented in Supplementary Table S11. The $\log _{2}$ ratio values from $\mathrm{qPCR}$ were plotted against $\log _{2}$ ratio values from the microarray analysis. A high correlation $\left(R^{2}=0.8\right)$ was obtained (Supplementary Fig. S2). Additionally, 50 of the 54 data points showed the same tendency of transcriptional modulation between the two methods. These results confirmed the reliability and accuracy of the microarray data in this study.

\section{Changes of phloem ultrastructure and phloem loading activity in HLB-affected rough lemon and sweet orange.}

Phloem plugging is considered to be a major factor inhibiting the transport of photosynthate in HLB-affected citrus plants and leads to starch accumulation in leaves and eventual tree decline (Achor et al. 2010; Etxeberria et al. 2009; Kim et al. 2009; Koh et al. 2012). Callose and phloem protein 2 are the two types of reported plugging materials deposited in the sieve elements of HLB-affected sweet orange leaves (Achor et al. 2010). However, thus far, callose deposition has not been demonstrated in the phloem of HLB-affected rough lemon.

A callose synthase (CALS) gene homologous to Arabidopsis CALS1 (AT1G05570) was upregulated by 1.8- and 5.4-fold (' $\mathrm{Ca}$. L. asiaticus' inoculated versus mock inoculated) at 27 WAI in rough lemon and sweet orange, respectively. It is suggestive that callose may also accumulate in the phloem tissue of infected rough lemon, though perhaps at a lesser rate. Observed under transmission electron microscopy (TEM), obvious accumulation of some smooth materials (presumed callose) was observed in the sieve elements of diseased rough lemon leaves with symptoms, compared with the basic level of callose formation in the mock-inoculated healthy controls (Fig. 5A and C). Moreover, collapse of phloem cells and starch accumulation can also be seen in the midribs of rough lemon symptomatic leaves, as well as in the same type of tissue from sweet orange (Fig. 5). In the HLB-affected but symptomless leaves, callose accumulation was sometimes found in a few sieve elements (by observing multiple sections) of both rough lemon and sweet orange samples but no phloem cell collapse was observed (Fig. 5B and E). These results indicate that the phloem ultrastructure of leaf midribs in ' $\mathrm{Ca}$. L. asiaticus'-infected rough lemon was affected as much as in infected sweet orange, and the transportation of photosynthate in phloem may be interrupted.

Detached leaves treated with a phloem tracer, 5,6-carboxyfluorescein diacetate (5,6-CFDA), were used to confirm the functionality of phloem loading and transport of in ' $\mathrm{Ca}$. L. asiaticus'-infected rough lemon and sweet orange. The green fluorescence of 5,6-CFDA spread all over the midribs and minor 
veins of healthy leaves from mock-inoculated rough lemon and sweet orange plants (Fig. 6); by contrast, a large amount of 5,6CF was deposited at the treated sites of HLB-affected symptomatic leaves, indicating an inhibition of phloem loading in both diseased rough lemon and sweet orange leaves. Surprisingly, the phloem transportation in the midribs of HLB-affected leaves revealed an obvious difference between diseased rough lemon and sweet orange. The fluorescence was clearly detected in the midribs of diseased rough lemon leaves, including leaves with and without symptoms (Fig. 6A). However, it was barely detected in the midribs of symptomatic sweet orange leaves; also, the fluorescence signal was much weaker in the midribs of leaves without symptoms than that in healthy controls (Fig. 6B). It was indicated that phloem loading and transport is severely interrupted in HLB-affected sweet orange but is substantially less affected in diseased rough lemon. The sustained transport activity in rough lemon phloem may be a significant explanation for the differences in disease progression and host growth between rough lemon and sweet orange.

\section{DISCUSSION}

Citrus species have shown significant differences in disease symptom development, growth rate, and survival period when infected with ' $\mathrm{Ca}$. L. asiaticus' but little is known at the genomic levels about these phenomena. It is critical to investigate and understand the mechanisms from all possible perspectives underlying the differences between susceptible and tolerant types, to facilitate the development of tolerant or even resistant varieties, or to adjust horticultural management to promote such tolerance. Prior to an ultimate solution, such adjustment to prolong the productive life of HLB-affected citrus trees would be useful to the industry; currently, many citrus growers in Florida have approached HLB management by enhanced fertilization applications, which have been successful to some degree, though the mechanism through which this occurs is currently unknown. Comparisons were made of the transcriptional changes of tolerant rough lemon and susceptible sweet orange after inoculation with ' $\mathrm{Ca}$. L. asiaticus' and during the subsequent disease development. It was shown that differentially expressed genes tended to be turned on or off earlier in infected rough lemon than in infected sweet orange, although a much more robust change in gene expression at 27 WAI was indicated in sweet orange than in rough lemon (Fig. 2). The contrast in gene expression responses between the two varieties likely indicates that timing of changes in expression patterns may be a critical factor for their differences in susceptibility (sensitivity) to the disease. Together with the results of anatomical analysis, the mechanisms of rough lemon tolerance and sweet orange susceptibility are discussed below.

Possible tolerance mechanisms of rough lemon to HLB.

Although callose-plugged phloem sieve elements and inhibition of phloem loading were observed in both HLB-diseased rough lemon and sweet orange leaves, phloem transport was less affected in the former than in the latter (Fig. 5). Less inhibition of phloem transport activities in symptomatic mature leaves of infected rough lemon may be due to formation of
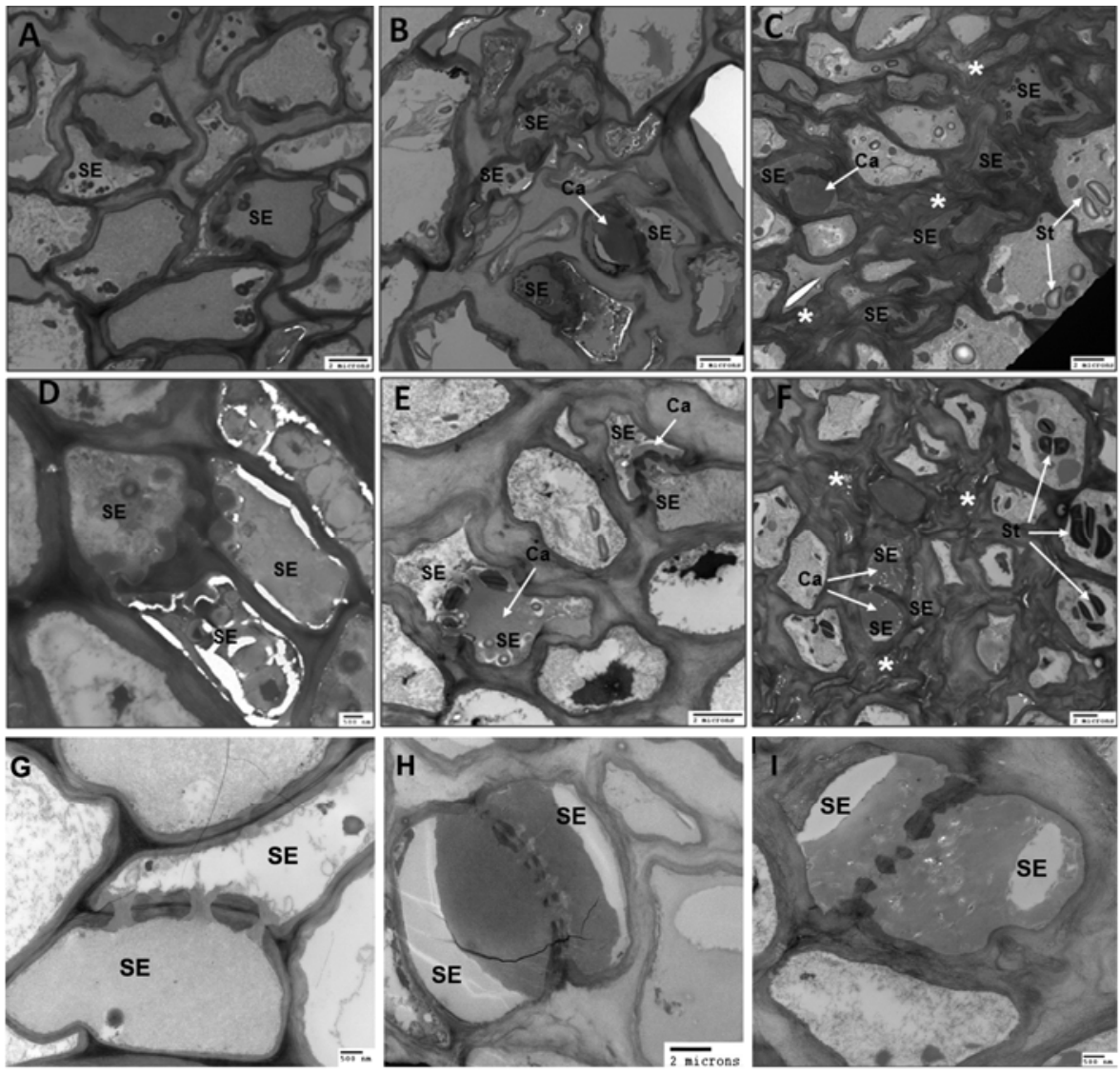

Fig. 5. Transmission electron micrographs of cross sections of leaf midribs from rough lemon and sweet orange (displaying the phloem area). A, B, and $\mathbf{C}$, Midribs from healthy leaves of mock-inoculated plants, leaves without symptoms, and leaves with symptoms from huanglongbing (HLB)-affected plants of rough lemon, respectively. D, E, and $\mathbf{F}$, Midribs from healthy leaves of mock-inoculated plants, leaves without symptoms, and leaves with symptoms from HLB-affected plants of sweet orange, respectively. G, Enlarged view of representative sieve element in midribs of mock-inoculated rough lemon or sweet orange; $\mathbf{H}$ and $\mathbf{I}$, enlarged view of plugged sieve elements in midribs from HLB-affected rough lemon and sweet orange, respectively. Ca, callose (presumed); SE, sieve element; St, starch; *, phloem cell collapse. Bars $=2 \mu \mathrm{m}(\mathrm{A}-\mathrm{C}, \mathrm{E}, \mathrm{F}$, and H) and $500 \mathrm{~nm}$ (D, G, and I). 
new functional phloem tissues, implicated by the upregulation of cell wall biosynthesis genes (Fig. 4). Interestingly, the root systems of diseased rough lemon plants in the greenhouse looked similar to those of the mock-inoculated plants 1 year after inoculation, whereas the root systems of diseased sweet orange plants had degraded substantially (J. Fan, C. Chen, R. H. Brlansky, F. G. Gmitter, Jr. unpublished data). It is likely that photosynthate was still transported in the phloem of affected rough lemon leaves to sink organs such as roots.

$\beta$-1,3-Glucanase can degrade callose ( $\beta$-1,3-glucan) and is suggested to be important in regulating callose deposition during pathogenesis (Beffa et al. 1996). A group of $\beta-1,3-$ glucanase genes was upregulated similarly at the late stage of HLB-affected rough lemon (Fig. 4) which, taken together with lesser upregulation of a CALS gene homologous to Arabidopsis CALS1 (AT1G05570), might result in decreasing the callose deposition to some extent in the phloem of diseased rough lemon plants. As a result, the consequence of phloem plugging can be less severe which, in turn, reduces the inhibition of phloem transport (Fig. 6). These factors might contribute to the recovery of infected rough lemon plants. By contrast, the considerable repression of $\beta$-1,3-glucanase genes observed in diseased sweet orange may lead to greater callose accumulation and, thus, severe interference with phloem transport. However, further research needs to be carried out to confirm the quanti-

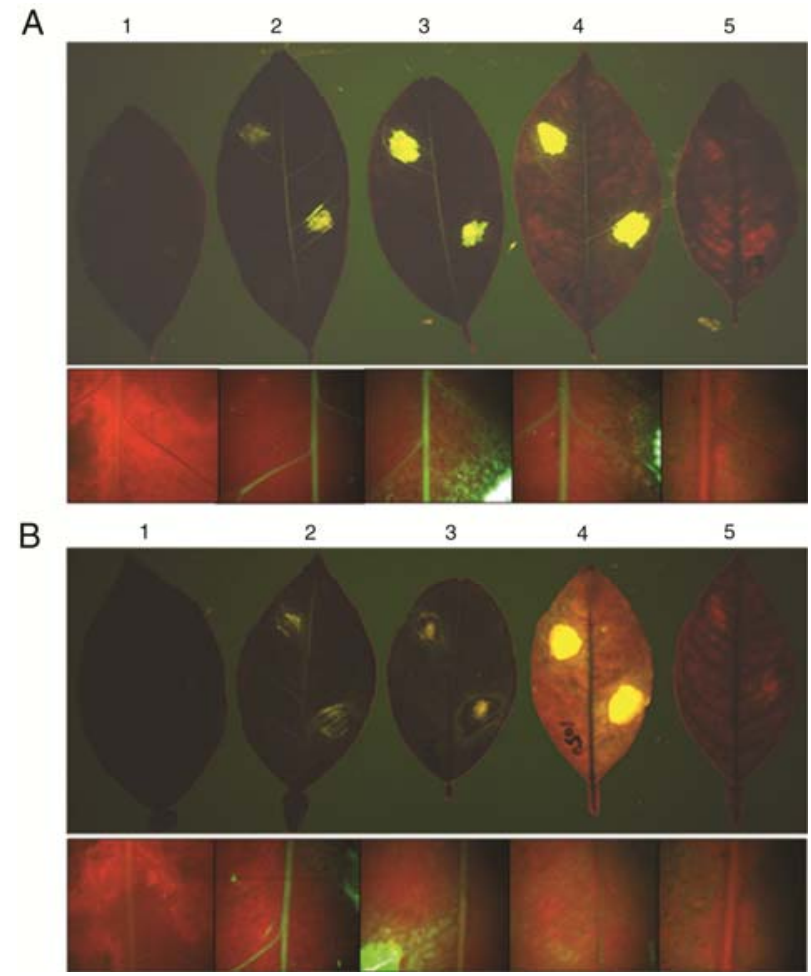

Fig. 6. Transportation of carboxyfluorescein in source leaves of $\mathbf{A}$, rough lemon and $\mathbf{B}$, sweet orange affected by huanglongbing. Lane 1, healthy leaves (from mock-inoculated plants) treated with water; lane 2, healthy leaves (from mock-inoculated plants) treated with 5,6-carboxyfluorescein diacetate (5,6-CFDA); lane 3, leaves without symptoms (from 'Candidatus Liberibacter asiaticus'-positive plants confirmed by quantitative polymerase chain reaction [qPCR]) treated with 5,6-CFDA; lane 4, leaves showing blotchy mottle symptoms (from 'Ca. L. asiaticus'-positive plants confirmed by qPCR) treated with 5,6-CFDA; lane 5, leaves showing blotchy mottle symptoms (from ' $\mathrm{Ca}$. L. asiaticus'-positive plants) treated with water. Pictures in the upper panels of A and B were taken under a Dark Reader Transilluminator DR-88M (Clare Chemical Research Inc.), and those in the lower panels were taken under a Stemi SV11 Fluorescent Microscope (Carl Zeiss). The green fluorescence in the leaves represents carboxyfluorescein. tative relation between the callose deposition in sieve elements and the inhibition of phloem transport. Meanwhile, the other type of phloem plugging material, PP2 protein, should be qualitatively and quantitatively compared between diseased rough lemon and sweet orange, because our results indicated that $p p 2$ gene expression was not significantly changed in HLB-affected rough lemon, though it was highly induced at 27 WAI in affected sweet orange. This result is similar to the findings of Albrecht and Bowman (2011b) that transcript levels for PP2 were not induced in tolerant US-897 in response to ' $\mathrm{Ca}$. L. asiaticus' infection but were dramatically elevated in susceptible Cleopatra mandarin.

AGP are a major class of structural proteins in the plant cell wall and play an important role in plant growth and development (Park et al. 2003). It is also suggested that AGP participates in stress-tolerance mechanisms, such as salt, water stress, and heat tolerance (Yamada et al. 2010). A fasciclin-like AGP (FLA) gene in Arabidopsis, AtFLA11, is likely involved in the formation of the secondary cell wall (Ito et al. 2005). XET is a key enzyme regulating cell wall expansion (Darley et al. 2001) and involved in many aspects of cell wall biosynthesis (e.g., the formation of secondary walls of xylem or phloem cells) (Bourquin et al. 2002). Secondary walls are essential for withstanding high turgor pressure in phloem sieve tubes. A set of genes encoding for cell wall protein AGP and XET were significantly induced at a late stage of HLB-affected rough lemon (Table 1), possibly leading to the change of secondary cell wall and the enhancement of tolerance to stresses such as high turgor pressure. Repression of these genes at a late stage of infected sweet orange may decrease the host ability to adapt to the ' $\mathrm{Ca}$. L. asiaticus'-altered cellular environment.

Altogether, maintaining or recovering of phloem transport activity and possible enhancement of stress tolerance may contribute to rough lemon tolerance to HLB. It likely represents a mechanism different from the HLB tolerance of US-897 that is suggested to be related to the high basal expression of defenseassociated genes (Albrecht and Bowman 2011b), presumably derived from its Poncirus parent. It should be noted that trees of Poncirus, a sexually compatible genus related to Citrus, are deciduous and undergo winter dormancy, are relatively slowergrowing, and exhibit several distinctive morphological differences in comparison with Citrus spp. Comparing two Citrus types much more closely related but with distinctive differences in HLB tolerance, such as rough lemon and sweet orange, highlights other additional host HLB-tolerance mechanisms that may be exploited for disease management.

\section{Delayed defense response may contribute \\ to HLB disease development of sweet orange.}

Global change of gene expression can be observed in both compatible and incompatible plant-pathogen interactions (Espinoza et al. 2007; Gibly et al. 2004). A critical difference between the two interactions is that timely recognition of the invading pathogen and rapid and intense activation of plant defense response occur in the latter. For instance, $P R$ genes are rapidly induced during an incompatible interaction in bacterial speck disease-resistant tomato plants (Jia and Martin 1999). At 27 WAI of ' $C a$. L. asiaticus' infection, an $R$-gene-mediated defense pathway, including a WRKY transcription factor, a mitogen-activated protein kinase RLP33, and many other defenserelated genes, was switched on in infected sweet orange (Fig. 4). It suggests that sweet orange is able to activate its defense mechanism at the late stage of HLB infection, similar to the results reported by our previous work (Fan et al. 2011) and the work of Kim and associates (2009) and Albrecht and Bowman (2011b). In addition, our results showed that inoculation of rough lemon and sweet orange with ' $\mathrm{Ca}$. L. asiaticus' did not 
result in any considerable induction of defense genes at early stages ( 5 and $17 \mathrm{WAI}$ ), inferring that both rough lemon- and sweet orange-' $C a$. L. asiaticus' interactions are compatible.

Activation of defense responses can lead to induction of programmed cell death and callose deposition which, in turn, prevents or slows the spread of pathogens. Nevertheless, our data demonstrated that the defense response of sweet orange was delayed until the late stage (27 WAI) of ' $\mathrm{Ca}$. L. asiaticus' infection, at which time the bacterium already reached high titer and likely spread throughout much of the plant's phloem system. Consequently, severe impairments of phloem ultrastructure and function such as phloem plugging (including callose and PP2 protein) and phloem necrosis occurred, as previously reported in HLB-diseased sweet orange (Achor et al. 2010; Etxeberria et al. 2009; Folimonova et al. 2009; Kim et al. 2009; Schneider 1967, 1968). In addition, loading and transport of photosynthate in the phloem of infected sweet orange were greatly inhibited (Fig. 6), which may lead to carbohydrate starvation of sink organs (e.g., roots) and quick tree decline (Etxeberria et al. 2009; Koh et al. 2012).

\section{Conclusion.}

Comparative transcriptional profiling results indicate that differential stress responses occur in rough lemon and sweet orange infected with ' $\mathrm{Ca}$. L. asiaticus'. Phloem transport activity in the midribs of leaves is considerably impaired in diseased sweet orange but much less significantly affected in infected rough lemon. The results highlight some underlying differences between tolerance and susceptibility mechanisms of divergent types of citrus to HLB disease. These results also provide potential candidate genes, such as those coding for cell wall proteins, $\beta$-1,3-glucanases, and GASA1, that might be manipulated for improving citrus tolerance or resistance to HLB by genetic engineering approaches.

\section{MATERIALS AND METHODS}

\section{Plant material.}

Two-year-old seedlings of rough lemon (C. jambhiri Lush.) and 'Madam Vinous' sweet orange ( $C$. sinensis L. Osbeck) were graft-inoculated with bud wood from ' $\mathrm{Ca}$. L. asiaticus'-infected 'Carrizo' citrange $(C$. sinensis L. Osbeck $\times P$. trifoliata L. Raf.) trees kept under greenhouse conditions to provide an inoculum source for various HLB-related experiments. For controls, the plants were grafted with bud wood from healthy Carrizo trees. All these plants were kept in a United States Department of Agriculture Animal and Plant Health Inspection Service and Center for Disease Control-approved and secured greenhouse at the University of Florida, Citrus Research and Education Center, Lake Alfred. Quantitative real-time PCR was performed to confirm the presence of ' $\mathrm{Ca}$. L. asiaticus' in the inoculum source and inoculated plants as described ( $\mathrm{Li}$ et al. 2006). Fully expanded leaves were sampled separately from three ' $\mathrm{Ca}$. L. asiaticus'-inoculated plants and three mock-inoculated plants (used as controls) of each species at 5, 17, and 27 WAI. Note that fully expanded leaves with HLB-specific symptoms were collected from infected plants at 27 WAI, representing an advanced stage of HLB disease development. For comparison of basal gene expression between rough lemon and sweet orange, fully expanded leaves were sampled separately from three healthy rough lemon and three healthy sweet orange plants before graft inoculation. Leaves were immediately frozen in liquid nitrogen and stored at $-80^{\circ} \mathrm{C}$ until use.

\section{RNA extraction and microarray experiments.}

Total RNA from each sample was extracted using the RNeasy plant mini kit (Qiagen, Valencia, CA, U.S.A.) and contaminated
DNA was eliminated with the DNA-free Kit (Ambion, Austin, TX, U.S.A.), according to the manufacturer's instructions; elimination of DNA was confirmed by qPCR and gel electrophoresis. The concentration of RNA was measured in a NanoDrop ND1000 spectrophotometer (NanoDrop Technologies, Wilmington, DE, U.S.A.). RNA quality was evaluated using an Agilent Bioanalyzer Model 2100 (Agilent Technologies, Palo Alto, CA, U.S.A.).

Microarray analysis using the Affymetrix microarray platform was performed at the Interdisciplinary Center for Biotechnology Research Microarray Core, University of Florida, Gainesville. According to the manufacturer's instructions, microarray experiments were carried out using the GeneChip 3' IVT Express kit and the GeneChip Citrus Genome array (containing up to 33,879 citrus transcripts) (Affymetrix, Santa Clara, CA, U.S.A.). Forty-two arrays, representing three ' $\mathrm{Ca}$. L. asiaticus'inoculated and three mock-inoculated (used as controls) individual biological replicates at 5, 17, and 27 WAI, and three individual biological replicates of baseline sample for each citrus species, were used in this study. Briefly, cDNA was synthesized from $250 \mathrm{ng}$ of total RNA and template for in vitro transcription, during which a biotin-modified nucleotide was incorporated. The biotin-labeled amplified RNA was then purified and fragmented. Samples were hybridized with rotation at $4^{\circ} \mathrm{C}$ for $16 \mathrm{~h}$ to the Affymetrix GeneChip Citrus Genome Arrays. The arrays were washed and stained with the reagents supplied in GeneChip hybridization wash and stain kit (Affymetrix) on an Affymetrix Fluidics Station 450 and were scanned with a GeneChip 7G Scanner (Affymetrix).

\section{Data analysis.}

The array data were analyzed using BioConductor, which is primarily based on the $\mathrm{R}$ programming language (Gentleman et al. 2004). Data normalization was performed by the Robust Multichip Analysis approach in an R package, Affy (Bolstad et al. 2003). Limma linear models were used to assess differential expression, and then an empirical Bayes method was applied to moderate the standard errors (Smyth 2004). FDR was generated by the Benjamini and Yekutieli approach (Benjamini and Yekutieli 2001). The microarray data are presented in accordance with the Minimum Information About a Microarray Experiment guidelines.

Due to the unavailability of citrus genome annotation at the time the data were analyzed, probe sets represented on the Affymetrix Citrus GeneChip were annotated by searching against the Arabidopsis thaliana genome via the HarvEST database. The corresponding Arabidopsis Genome Initiative numbers of Arabidopsis orthologs were used instead of probe ID numbers on the Affymetrix Citrus GeneChip for the following analyses. Differentially expressed probe sets $(P \leq 0.05)$ were used to identify significantly changed pathways at each time point. Pathway analysis was performed using PageMan (Usadel et al. 2006), which is a built-in application in the freedownloadable software MapMan. A Wilcoxon test was applied and a statistics-based overview of changed pathways from global gene expression alterations was provided. The same data sets were also imported into MapMan to map the differentially expressed genes into specific pathways. It should be noted that multiple probe sets from citrus genome microarray may be annotated to the same gene from Arabidopsis genome. In this case, average expression data of these probe sets were used, since no duplicate gene can be imported into MapMan.

\section{qPCR.}

The same RNA samples used for microarray experiments were also used for qPCR. RT was performed with the QuantiTect Reverse Transcription Kit (Qiagen) according to the manu- 
facturer's instruction. Briefly, $1 \mu \mathrm{g}$ of total RNA was incubated with $7 \times$ gDNA Wipeout Buffer at $42^{\circ} \mathrm{C}$ for $5 \mathrm{~min}$. The reaction mixture was then added into RT master mix in a final volume of $20 \mu \mathrm{l}$, incubated at $42^{\circ} \mathrm{C}$ for $30 \mathrm{~min}$, and inactivated at $95^{\circ} \mathrm{C}$ for $3 \mathrm{~min}$.

qPCR was carried out in an Applied Biosystems 7500 Fast system (Applied Biosystems, Inc., Foster City, CA, U.S.A.) using a QuantiTect SYBR Green PCR Kit (Qiagen). A reaction mixture $(20 \mu \mathrm{l})$ consisted of $2 \times$ QuantiTect SYBR Green PCR Master mix, $0.3 \mu \mathrm{M}$ each primer, and $1 \mu \mathrm{l}$ of the finished RT reaction. qPCR was started from one cycle at $95^{\circ} \mathrm{C}$ for $15 \mathrm{~min}$, followed by 40 cycles at $94^{\circ} \mathrm{C}$ for $15 \mathrm{~s}, 58^{\circ} \mathrm{C}$ for $30 \mathrm{~s}$, and $72^{\circ} \mathrm{C}$ for $30 \mathrm{~s}$. Melting curve analysis and electrophoresis were performed to verify the specificity and identity of the qPCR products. In total, six replicates were used for each sample (three biological replicates $\times$ two technical replicates).

Glyceraldehyde 3-phosphate dehydrogenase was used as a reference gene to provide relative quantification for the target genes upon ' $\mathrm{Ca}$. L. asiaticus' infection (Mafra et al. 2012). Primer sequences were listed in Supplementary Table S12. PCR efficiencies of the reference and target genes were determined by generating standard curves based on serial dilutions of sweet orange genomic DNA, which was extracted from tender leaves using the cetyltrimethylammonium bromide method (Doyle and Doyle 1990). The amplification efficiency was automatically calculated using the 7500 Fast system SDS software. The relative quantification of gene expression level was determined by the comparative $\mathrm{C}_{\mathrm{T}}$ method $2^{-\Delta \Delta \mathrm{CT}}$ (Livak and Schmittgen 2001), where $\Delta \Delta \mathrm{C}_{\mathrm{T}}=\left(\mathrm{C}_{\mathrm{T}} \text {, target }-\mathrm{C}_{\mathrm{T}} \text {, reference }\right)_{\mathrm{HLB}}-$ $\left(\mathrm{C}_{\mathrm{T}} \text {, target }-\mathrm{C}_{\mathrm{T}} \text {, reference }\right)_{\text {Control. }}$ Standard deviation and $P$ value were calculated using a simple $t$ test in SAS 9.1 (SAS Institute, Cary, NC, U.S.A.) as described by Yuan and associates (2006).

\section{TEM and phloem loading assessment.}

Fully expanded leaves were collected from the same set of plants used in microarray experiments. One year after inoculation, multiple leaves with and without symptoms were sampled from at least three ' $\mathrm{Ca}$. L. asiaticus'-infected plants; healthy leaves were sampled from mock-inoculated plants as controls. For TEM, leaf midribs were cut in pieces approximately 2 to 3 $\mathrm{mm}^{2}$ and processed as described by Etxeberria and associates (2009). Micrographs were taken with an AMT digital camera (Advanced Microscopy Techniques Corp., Danver, MA, U.S.A.) connected to a Morgagni 268 transmission electron microscope (FEI Company, Hillsboro, OR, U.S.A.).

Phloem-loading experiments were carried out with detached leaf samples based on the method of Roberts and associates (1997), with modifications. Briefly, approximately $1 \mathrm{~cm}^{2}$ of the abaxial surface at two sites of each leaf was gently abraded with fine sandpaper, and $10 \mu \mathrm{l}$ of 5,6-CFDA at $300 \mu \mathrm{g} / \mathrm{ml}$ was applied to each abraded area. Leaves treated with equal amounts of distilled water were used as controls for assessing tissue autofluorescence. After $24 \mathrm{~h}$, the leaves were observed for fluorescence under a Dark Reader Transilluminator DR88M (Clare Chemical Research Inc., Dolores, CO, U.S.A.), and photos were taken with a Nikon D80 digital camera (Nikon Corporation, Tokyo). Higher magnification pictures were made under a fluorescence stereomicroscope Stemi SV11 (Carl Zeiss, Oberkochen, Germany).

\section{ACKNOWLEDGMENTS}

This work was partially supported by the China Scholarship Council and by a grant from the Florida Citrus Research and Development Foundation. We thank M. Wendell, B. Clarke, G. Ananthakrishnan, and the Interdisciplinary Center for Biotechnology Research Microarray Core (University of Florida) for their excellent technical support.

\section{LITERATURE CITED}

Achor, D. S., Etxeberria, E., Wang, N., Folimonova, S. Y., Chung, K. R., and Albrigo, L. G. 2010. Sequence of anatomical symptom observations in citrus affected with huanglongbing disease. Plant Pathol. J. 9:56-64.

Affymetrix. 2004. Sample pooling for microarray analysis: A statistical assessment of risks and biases. Affymetrix Tech. Note No. 701494 Rev. 2. Affymetrix Corp., Santa Clara, CA, U.S.A. Published online.

Albrecht, U., and Bowman, K. D. 2008. Gene expression in Citrus sinensis (L.) Osbeck following infection with the bacterial pathogen Candidatus Liberibacter asiaticus causing Huanglongbing in Florida. Plant Sci. 175:291-306.

Albrecht, U., and Bowman, K. D. 2011a. Tolerance of the trifoliate citrus hybrid US-897 (Citrus reticulata Blanco $\times$ Poncirus trifoliata L. Raf.) to huanglongbing. HortScience 46:16-22.

Albrecht, U., and Bowman, K. D. 2011b. Transcriptional response of susceptible and tolerant citrus to infection with Candidatus Liberibacter asiaticus. Plant Sci. 185-186:118-130.

Beffa, R. S., Hofer, R. M., Thomas, M., and Meins, F. 1996. Decreased susceptibility to viral disease of beta-1,3-glucanase-deficient plants generated by antisense transformation. Plant Cell 8:1001-1011.

Benjamini, Y., and Yekutieli, D. 2001. The control of the false discovery rate in multiple testing under dependency. Ann. Stat. 29:1165-1188.

Bolstad, B. M., Irizarry, R. A., Astrand, M., and Speed, T. P. 2003. A comparison of normalization methods for high density oligonucleotide array data based on variance and bias. Bioinformatics 19:185-193.

Bourquin, V., Nishikubo, N., Abe, H., Brumer, H., Denman, S., Eklund, M., Christiernin, M., Teeri, T. T., Sundberg, B., and Mellerowicz, E. J. 2002. Xyloglucan endotransglycosylases have a function during the formation of secondary cell walls of vascular tissues. Plant Cell 14:30733088 .

Bove, J. M. 2006. Huanglongbing: A destructive, newly-emerging, century-old disease of citrus. J. Plant Pathol. 88:7-37.

Darley, C. P., Forrester, A. M., and McQueen-Mason, S. J. 2001. The molecular basis of plant cell wall extension. Plant Mol. Biol. 47:179-195.

Doyle, J. J., and Doyle, J. L. 1990. Isolation of plant DNA from fresh tissue. Focus 12:13-15.

Espinoza, C., Vega, A., Medina, C., Schlauch, K., Cramer, G., and ArceJohnson, P. 2007. Gene expression associated with compatible viral diseases in grapevine cultivars. Funct. Integr. Genomics 7:95-110.

Etxeberria, E., Gonzalez, P., Achor, D., and Albrigo, G. 2009. Anatomical distribution of abnormally high levels of starch in HLB-affected Valencia orange trees. Physiol. Mol. Plant Pathol. 74:76-83.

Fan, J., Chen, C., Brlansky, R. H., Gmitter, F. G., Jr., and Li, Z.-G. 2010. Changes in carbohydrate metabolism in Citrus sinensis infected with 'Candidatus Liberibacter asiaticus'. Plant Pathol. 59:1037-1043.

Fan, J., Chen, C., Yu, Q., Brlansky, R. H., Li, Z.-G., and Gmitter, F. G., Jr. 2011. Comparative iTRAQ proteome and transcriptome analyses of sweet orange infected by "Candidatus Liberibacter asiaticus". Physiol. Plant. 143:235-245.

Folimonova, S. Y., Robertson, C. J., Garnsey, S. M., Gowda, S., and Dawson, W. O. 2009. Examination of the responses of different genotypes of citrus to Huanglongbing (citrus greening) under different conditions. Phytopathology 99:1346-1354.

Gentleman, R. C., Carey, V. J., Bates, D. M., Bolstad, B., Dettling, M., Dudoit, S., Ellis, B., Gautier, L., Ge, Y. C., Gentry, J., Hornik, K., Hothorn, T., Huber, W., Iacus, S., Irizarry, R., Leisch, F., Li, C., Maechler, M., Rossini, A.J., Sawitzki, G., Smith, C., Smyth, G., Tierney, L., Yang, J. Y. H., and Zhang, J. H. 2004. Bioconductor: Open software development for computational biology and bioinformatics. Genome Biol. 5:R80.

Gibly, A., Bonshtien, A., Balaji, V., Debbie, P., Martin, G. B., and Sessa, G. 2004. Identification and expression profiling of tomato genes differentially regulated during a resistance response to Xanthomonas campestris pv. vesicatoria. Mol. Plant-Microbe Interact. 17:1212-1222.

Hammond-Kosack, K. E., and Jones, J. D. G. 1996. Resistance genedependent plant defense responses. Plant Cell 8:1773-1791.

Harmer, S. L., Hogenesch, J. B., Straume, M., Chang, H. S., Han, B., Zhu, T., Wang, X., Kreps, J. A., and Kay, S. A. 2000. Orchestrated transcription of key pathways in Arabidopsis by the circadian clock. Science 290:2110-2113.

Ito, S., Suzuki, Y., Miyamoto, K., Ueda, J., and Yamaguchi, I. 2005. AtFLA11, a fasciclin-like arabinogalactan-protein, specifically localized in sclerenchyma cells. Biosci. Biotechnol. Biochem. 69:19631969.

Jia, Y., and Martin, G. B. 1999. Rapid transcript accumulation of pathogenesis-related genes during an incompatible interaction in bacterial speck disease-resistant tomato plants. Plant Mol. Biol. 40:455-465.

Kim, J. S., Sagaram, U. S., Burns, J. K., Li, J. L., and Wang, N. 2009. Response of sweet orange (Citrus sinensis) to 'Candidatus Liberibacter 
asiaticus' infection: Microscopy and microarray analyses. Phytopathology 99:50-57.

Koh, E.-J., Zhou, L., Williams, D. S., Park, J., Ding, N., Duan, Y.-P., and Kang, B.-H. 2012. Callose deposition in the phloem plasmodesmata and inhibition of phloem transport in citrus leaves infected with "Candidatus Liberibacter asiaticus". Protoplasma 249:687-97.

Koizumi, M., Prommintara, M., Linwattana, G., and Kaisuwan, T. 1993. Field evaluation of citrus cultivars for greening disease resistance in Thailand. In: Proc. 12th Conf. Int. Organ. Citrus Virol. New Delhi, India.

Li, W. B., Hartung, J. S., and Levy, L. 2006. Quantitative real-time PCR for detection and identification of Candidatus Liberibacter species associated with citrus huanglongbing. J. Microbiol. Methods 66:104-115.

Livak, K. J., and Schmittgen, T. D. 2001. Analysis of relative gene expression data using real-time quantitative PCR and the $2(\mathrm{~T})(-$ delta delta C) method. Methods 25:402-408.

Mafra, V., Kubo, K. S., Alves-Ferreira, M., Ribeiro-Alves, M., Stuart, R. M., Boava, L. P., Rodrigues, C. M., and Machado, M. A. 2012. Reference genes for accurate transcript normalization in citrus genotypes under different experimental conditions. PLoS One 7:e31263. Published online.

Nagaoka, S., and Takano, T. 2003. Salt tolerance-related protein STO binds to a Myb transcription factor homologue and confers salt tolerance in Arabidopsis. J. Exp. Bot. 54:2231-2237.

Nomura, K., Melotto, M., and He, S. Y. 2005. Suppression of host defense in compatible plant-Pseudomonas syringae interactions. Curr. Opin. Plant Biol. 8:361-368.

O’Donnell, P. J., Schmelz, E. A., Moussatche, P., Lund, S. T., Jones, J. B. and Klee, H. J. 2003. Susceptible to intolerance-a range of hormonal actions in a susceptible Arabidopsis pathogen response. Plant J. 33:245257.

Park, M. H., Suzuki, Y., Chono, M., Knox, J. P., and Yamaguchi, I. 2003. CsAGP1, a gibberellin-responsive gene from cucumber hypocotyls, encodes a classical arabinogalactan protein and is involved in stem elongation. Plant Physiol. 131:1450-1459.

Raffaele, S., Vailleau, F., Leger, A., Joubes, J., Miersch, O., Huard, C., Blee, E., Mongrand, S., Domergue, F., and Roby, D. 2008. A MYB transcription factor regulates very-long-chain fatty acid biosynthesis for activation of the hypersensitive cell death response in Arabidopsis. Plant Cell 20:752-767.

Rawat, R., Schwartz, J., Jones, M. A., Sairanen, I., Cheng, Y., Andersson, C. R., Zhao, Y., Ljung, K., and Harmer, S. L. 2009. REVEILLE1, a Myb-like transcription factor, integrates the circadian clock and auxin pathways. Proc. Natl. Acad. Sci. U.S.A. 106:16883-16888.

Roberts, A. G., Cruz, S. S., Roberts, I. M., Prior, D., Turgeon, R., and Oparka, K. J. 1997. Phloem unloading in sink leaves of Nicotiana benthamiana: Comparison of a fluorescent solute with a fluorescent virus. Plant Cell 9:1381-1396.
Schaffer, R., Ramsay, N., Samach, A., Corden, S., Putterill, J., Carre, I. A and Coupland, G. 1998. The late elongated hypocotyl mutation of Arabidopsis disrupts circadian rhythms and the photoperiodic control of flowering. Cell 93:1219-1229.

Schneider, H. 1967. Phloem necrosis associated with the greening disease of sweet orange (Citrus sinensis). Phytopathology 57:829.

Schneider, H. 1968. Anatomy of greening-disease sweet orange shoots. Phytopathology 58:1155-1160.

Smyth, G. K. 2004. Linear models and empirical Bayes methods for assessing differential expression in microarray experiments. Stat. Appl. Genet. Mol. Biol. 3:Article3.

Teixeira, D. C., Saillard, C., Couture, C., Martins, E. C., Wulff, N. A., Eveillard-Jagoueix, S., Yamamoto, P. T., Ayres, A. J., and Bove, J. M. 2008. Distribution and quantification of Candidatus Liberibacter americanus agent of huanglongbing disease of citrus in Sao Paulo State, Brasil, in leaves of an affected sweet orange tree as determined by PCR. Mol. Cell. Probe. 22:139-150.

Thimm, O., Blasing, O., Gibon, Y., Nagel, A., Meyer, S., Kruger, P., Selbig, J., Muller, L. A., Rhee, S. Y., and Stitt, M. 2004. MAPMAN: A user-driven tool to display genomics data sets onto diagrams of metabolic pathways and other biological processes. Plant J. 37:914-939.

Usadel, B., Nagel, A., Steinhauser, D., Gibon, Y., Blasing, O. E., Redestig, H., Sreenivasulu, N., Krall, L., Hannah, M. A., Poree, F., Fernie, A. R., and Stitt, M. 2006. PageMan: An interactive ontology tool to generate, display, and annotate overview graphs for profiling experiments. BMC Bioinf. 7:535.

Vailleau, F., Daniel, X., Tronchet, M., Montillet, J. L., Triantaphylides, C., and Roby, D. 2002. A R2R3-MYB gene, AtMYB30, acts as a positive regulator of the hypersensitive cell death program in plants in response to pathogen attack. Proc. Natl. Acad. Sci. U.S.A. 99:10179-10184.

Wang, Z. Y., and Tobin, E. M. 1998. Constitutive expression of the CIRCADIAN CLOCK ASSOCIATED 1 (CCA1) gene disrupts circadian rhythms and suppresses its own expression. Cell 93:1207-1217.

Yamada, A., Ozeki, Y., and Akatsuka, S. October 2010. Arabinogalactan protein having activity of improving tolerance to heat or moisture stress. U.S. patent 11/573,010(11/573,010).

Yuan, J. S., Reed, A., Chen, F., and Stewart, C. N. 2006. Statistical analysis of real-time PCR data. BMC Bioinf. 7:85.

Zhao, X. 1981. Citrus yellow shoot disease (Huanglongbing)-A review. Proc. Int. Soc. Citricult. 1:466-469.

\section{AUTHOR-RECOMMENDED INTERNET RESOURCES}

BioConductor database: www.bioconductor.org

HarvEST database:

harvest-web.org/hweb/bin/chipsearch.wc?wsize $=1259 \times 608$

MapMan database: www.gabipd.org/projects/MapMan 